\title{
Translating Qualitative Data into Intervention Content Using the Theoretical Domains Framework and Stakeholder Co-Design: A Worked Example from a Study of Cervical Screening Attendance in Older Women
}

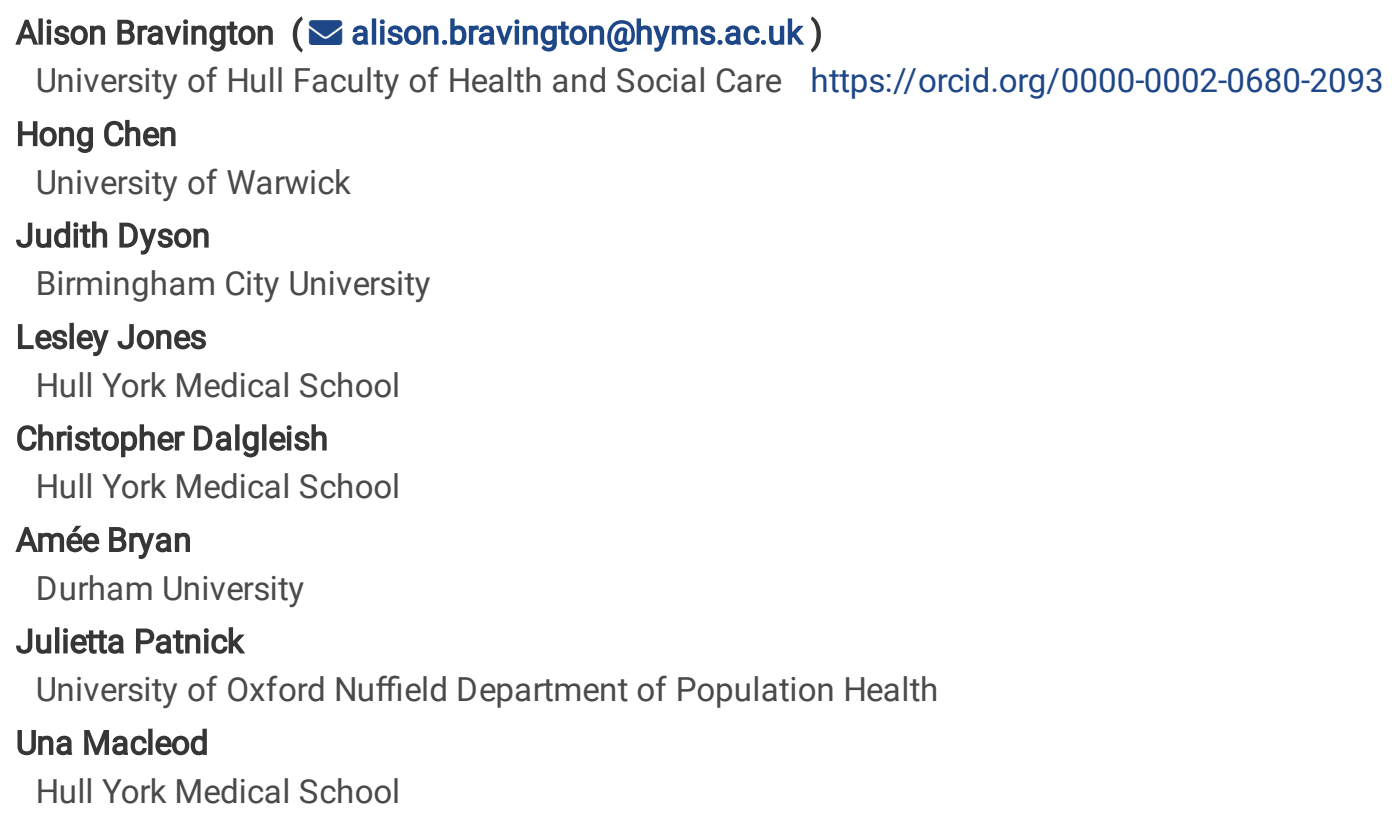




\section{Abstract}

Background: Previous screening interventions have demonstrated a series of features related to social determinants which have increased uptake in targeted populations, including the assessment of health beliefs and barriers to screening attendance as part of intervention development. Many studies cite the use of theory to identify methods of behaviour change, but fail to describe in detail how theoretical constructs are transformed into intervention content. The aim of this study was to use data from qualitative exploration of cervical screening in women over fifty in the UK as the basis of intervention co-design with stakeholders using behavioural change frameworks. We describe the identification of behavioural mechanisms from qualitative data, and how these were used to develop content for a service user leaflet and a short video animation for practitioner training. The interventions aimed to encourage sustained commitment to cervical screening among women over fifty, and to increase sensitivity to age-related problems in cervical screening among primary care practitioners.

Methods: We translated qualitative data into barriers and facilitators by recoding a primary data set, and subsequently applied the Theoretical Domains Framework (TDF) to identify relevant behaviour change techniques (BCTs) based on the data set. Key TDF domains and associated BCTs were presented in stakeholder focus groups to guide intervention content and mode of delivery.

Results: Behavioural determinants relating to attendance clustered under three domains: beliefs about consequences, emotion and social influences, which mapped to three BCTs respectively: (1) persuasive communication/information provision; (2) stress management; (3) role modelling and encouragement. Service-user stakeholders translated these into three pragmatic intervention components: (i) addressing unanswered questions, (ii) problem-solving practitioner challenges and (iii) peer group communication. Based on (ii), practitioner stakeholders developed a call to action in three areas - clinical networking, history-taking, and flexibility in screening processes. APEASE informed modes of delivery (a service-user leaflet and a cartoon animation for practitioners).

Conclusion: The application of the TDF to qualitative data can provide an auditable protocol for the translation of qualitative data into intervention content.

\section{Contributions To The Literature}

- Interventions to encourage cervical screening in European countries are largely based around information provision, but evidence suggests that raising awareness does not necessarily translate into attendance for screening tests.

- The use of theories of behaviour change to guide intervention development has begun to address the gap between consciousness-raising and action, but the relationship between theory and intervention content is rarely made explicit.

- This paper answers recent calls for explanations of how theory is used to develop interventions. It provides a step-by-step explanation of the translation of qualitative data about cervical screening into intervention content which is replicable in other contexts.

\section{Background}

Cancer of the cervix is one of the most preventable forms of the disease: pre-cancerous cells can be identified using a screening test and treated before they develop into cancer. Public cervical screening programmes are provided in many countries, but do not generally reach target participation rates ${ }^{[1]}$. Reviews of interventions to encourage screening uptake demonstrate that cervical screening programmes face different challenges to breast and colorectal screening ${ }^{[2,3]}$. Cancer screening is targeted by age and gender: in England, women aged 50 to 70 are invited for breast screening, men and women aged 60 to 74 for colorectal cancer screening and women aged 25 to 64 for cervical screening. Cervical screening is stratified further, transitioning from 3-yearly to 5yearly screening from the age of fifty.

Cervical screening also differs from breast and colorectal screening in other ways. Screening the cervix is an invasive procedure, requiring a sample from inside an intimate area of the body. Having this procedure carried out by a GP or practice nurse can cause embarrassment or distress ${ }^{[4,5]}$. Health beliefs surrounding cervical cancer can also affect attendance - for example, stigma and perceptions of risk arising from the association of cervical cancer with promiscuity ${ }^{[6,7,8]}$. Research into barriers that keep women from attending for screening suggests that a multiplicity of demographic and cultural factors also contribute to decision-making ${ }^{[9}$, 
${ }^{10]}$, in addition to health knowledge and structural issues such as the costs associated with taking time off work or travelling to appointments $^{[5,11]}$.

In 2019-20, a preliminary test was introduced for human papillomavirus (HPV), a common, symptomless infection which can be contracted from a single sexual contact and is the main causal factor in the development of cervical cancer. Prior to this test becoming standard in the UK, all screening samples were subject to cytology (examining cells from the cervix for pre-cancerous changes); under current protocols, only those which are positive for a high-risk strain of HPV are now taken forward. Vaccination to protect against HPV was introduced for girls aged 12-13 in the UK in 2008, with the eldest girls to benefit now aged 30-31. The vaccine is ineffective in women who have already been exposed to HPV - it cannot be used in women who are already sexually active, leaving them at greater risk. Home testing for HPV is currently being trialled in the UK ${ }^{[12]}$; if this approach is successful, women over fifty will need encouragement to engage with home testing. Where a HPV test is positive, they will subsequently need to attend their GP surgery for a cervical screening test.

Among the demographic factors, age is now playing a key role in the challenges facing cervical screening programmes. In the UK, a quarter of women aged 50 to 64 do not attend free screening offered by the National Health Service, and rates for attendance drop further at the top of this age range $\mathrm{e}^{[13,14,15,16]}$. Evidence suggests that women over 45 are more likely to make the decision to stop attending than younger women ${ }^{[5,8]}$, to cite past traumatic experiences as a reason for non-attendance ${ }^{[4,18,19]}$, and to experience the screening procedure as more painful ${ }^{[20]}$. Current evidence predicts a potential rise of more than $60 \%$ in rates of cervical cancer among older women by $2036^{[21]}$, suggesting an urgent need for targeted interventions to engage women in this cohort with home testing and cervical screening.

The impact of initiatives to encourage screening uptake is often low, localised or short term ${ }^{[7,22,23,24]}$. In the European literature, interventions are largely task-focused, based on raising awareness by altering the content or source of information provision ${ }^{[2,3]}$. Evidence from Africa and America suggests that consciousness-raising alone, while increasing women's knowledge and awareness of the benefits of screening, does not necessarily translate into action $[6,7,24,25,26]$. Engagement with screening requires behavioural change, and behavioural change is shaped by social and environmental context. Successful interventions beyond Europe have often developed around community education initiatives, and demonstrate how stakeholder involvement in intervention development can tailor interventions to fit local social and cultural contexts ${ }^{[27,28,29]}$.

In the UK, Medical Research Council (MRC) guidelines for complex interventions ${ }^{[30]}$ and National Institute for Health and Care Excellence guidelines $^{[31,32]}$ emphasise the need to ground behaviour change within a theoretical framework. The explicit use of theory also allows us to understand the mechanisms of influence of such interventions and to replicate these ${ }^{[33]}$. Systematic review evidence demonstrates the effectiveness of the application of theory in this way ${ }^{[34,35,36]}$. Studies which have used behavioural theories to develop their interventions have shown more success in increasing screening rates ${ }^{[37,38]}$. Crucially, these interventions take social determinants into account ${ }^{[3]}$ - those that influence women's attitudes and health beliefs, including, for example, factors shaping women's past experiences of screening and perceptions of risk.

Previous interventions demonstrate a series of features related to social determinants which have increased screening uptake in targeted populations, including cultural adaptation ${ }^{[39]}$, peer education and community engagement ${ }^{[40]}$, as well as the assessment of health beliefs and barriers as part of intervention development ${ }^{[25]}$. However, although many studies cite the use of theory to identify methods of behaviour change, they fail to describe in detail how theoretical constructs are transformed into intervention content ${ }^{[41}$, 42]. Current debate about the efficacy of behavioural theory interventions has led to the labelling of such studies as 'theory inspired' rather than 'theory based' ${ }^{[43]}$. Theory based interventions take the additional step of reporting how theory maps on to intervention content - a level of transparency that enables more effective evaluation ${ }^{[3]}$. However, detailed descriptions of how study data is translated into intervention content remain sparse in the literature ${ }^{[44]}$.

Literature in other areas of health care illustrates how thematic analysis using the TDF can inform interventions ${ }^{[45,46,47]}$, but methods for achieving this have not been explicitly described with respect to cervical screening. In this paper, our aim is to describe how barriers and facilitators to attending cervical screening, identified in qualitative data from a primary research study grounded in a constructionist epistemology ${ }^{[48]}$, were categorised into the domains of the $\operatorname{TDF}^{[49]}$ and used to identify appropriate behaviour 
change techniques ${ }^{[50]}$. We then describe the stakeholder co-design of the content and mode of delivery of two pragmatic interventions: a service-user leaflet and a video animation for practitioners, for use in primary care (doctors' surgeries and associated health networks) in the UK.

\section{Methods}

\section{Study design and setting}

The research team undertook a preliminary qualitative study to explore the social, environmental and contextual influences on the experience of cervical screening in women over the age of fifty in the UK, and the decision to attend for screening tests. This study took place in the north of England between 2016 and 2018 in two locations where attendance for screening was lower than the national average, recruiting women over fifty and screening practitioners in primary care. Interviews took a phenomenological approach, focusing on the elicitation of patient and practitioner experiences of cervical screening. In-depth interviews with 25 women over fifty (attenders and non-attenders) and 28 cervical screening practitioners were conducted by a non-clinical female researcher over the age of fifty with a background in psychology/sociology ( $A B)$. Data from the primary study were coded using thematic analysis, first through collaborative analysis $\left(A B^{1}, A B^{3}, C D, H C\right)$, and the coding framework was subsequently refined in an iterative process. ${ }^{[51]}$.

Behavioural change theory (BCT) in the form of the Theoretical Domains Framework (a precursor of the framework of mechanisms of action, now more fully developed by Michie and colleagues ${ }^{[52]}$ ) was chosen as a pragmatic approach to developing intervention content from our primary data. The TDF comprehensively synthesised constructs from behavioural models, and offered a pragmatic, structured methodology for connecting exploratory qualitative data with appropriate behaviour change techniques. The clarity and simplicity of the framework also made it amenable to description in a way that can be understood by a range of stakeholders.

BCT theory was applied by recoding the primary qualitative data set to draw out statements describing barriers and facilitators of attendance in a collaborative session involving three members of the research team (AB $\left.{ }^{1}, J D, H C\right)$. Barrier and facilitator statements were categorised using the TDF to identify key domains ${ }^{[49]}$, and the behavioural change techniques associated with these domains ${ }^{[50]}$. The primary study and barrier and facilitator data were described to stakeholders in one lay focus group (FG1) and two practitioner focus groups (FG2, FG3) convened in 2017 and 2018 in the two urban districts involved in the primary interview study. Focus groups were audio recorded, transcribed verbatim and anonymised; recordings were placed in secure data storage at the University of Hull. The focus groups formulated target behaviours for two interventions (one for service-users, one for practitioners), and designed intervention content based on the behavioural change techniques associated with key domains identified using the TDF. Interventions were then developed by the research team based on the focus group discussions, intended for implementation via primary care networks (general practitioner surgeries) in the UK.

\section{Sampling and recruitment of stakeholders for intervention development}

FG1 was convened by the research team by inviting service-users interviewed as part of the qualitative study to take part; five interviewees between the ages of 55 and 64 volunteered to assist with the co-design of an intervention (two had stopped attending for screening, two delayed attendance for complex reasons, and one attended regularly). The practitioner focus groups (FG2 and FG3) were recruited by three practitioners interviewed for the qualitative study, and included 11 further screening practitioners from their local primary care networks. FG2 involved four GPs and four practice nurses; FG3, recruited from a different location, included one GP and five practice nurses.

\section{Intervention development procedure}

The target behaviour specified was attendance for cervical screening in women over fifty. Intervention development subsequently involved three stages: the recoding of qualitative data to produce a set of barrier and facilitator statements, the categorisation of barrier and facilitator statements into domains following the TDF, and service user and practitioner focus groups to facilitate the stakeholder co-design of intervention content from both perspectives. See Figure 1 for a flow diagram of procedures.

Stage 1 - Recoding of qualitative data set: The data set from the primary qualitative study focused on women's experiences of cervical screening; the interviewer probed for barriers and facilitators of attendance based on the experiences the women chose to 
share. Barriers and facilitators were explored from the perspective of health care professionals in interviews with general practitioners and practice nurses about their experiences of conducting cervical screening with women over fifty.

The thematic coding template developed in the original qualitative study was used as a guide to draw out statements representing barriers and facilitators of attendance (AB). Themes exploring women's difficult previous screening experiences, myths and misunderstandings surrounding screening, and the challenges faced by practitioners contributed data representing barriers. Themes exploring family health talk, sexual health and relationships, and history-taking and rapport-building during appointments contributed data representing facilitators. Less prevalent barriers and facilitators were noted where they appeared elsewhere in the data - for example, knowledge deficits and environmental influences (for example, perceived difficulties with screening equipment where women associated the procedure with a metal speculum and scraper used in earlier decades rather than the present-day plastic speculum and brush).

Multiple quotations from the qualitative data represented similar concepts. The statements were read by three research team members ( $A B, J D, H C)$, and in a full day collaborative analysis session, the team pooled similar quotations into two sets of summary statements representing barriers and facilitators in preparation for stage 2 (see Table 1 for examples). 
Table 1

Examples of data contributing to summary statements, and of TDF domains matching the statements.

\section{EXAMPLES OF DATA}

'I just wonder if it's perhaps in a family history of when, like, I suppose if there's been one or more people, like two or three people in your family that have had it, I would imagine that that would actually raise your risk of it...Maybe people that have been sort of a bit promiscuous, prone to infection, something like that might trigger it.' Attender (LS24 $\left.{ }^{1}\right)$

I've been with my husband since I was eighteen, we're still together. I'm pretty certain he's monogamous...I'm certainly monogamous, so I don't feel like I'm at risk.'Attender (LS17)

'She [practitioner] should have sat me down in the first place, ascertained any problems around the smear - what do I understand about it? She never did any of that, it was just a question of the mechanics of it. So I, I want an explanation.' Non-attender (LS2)

'I think they just feel that if it was going to happen it should have all have happened by now - and that's it

for me now, just, my ovaries are switched off, it's, everything's winding down or wound down and that's it.'

$\mathrm{GP}\left(\mathrm{HCP}^{2}\right)$

'I might be just in my sixties now but I mean I'm still... I'm quite a young sixty, erm and I'm still having a sex life... I've been pushed on the scrap heap, they don't wanna know!' Attender (LS19)

'I've been wondering at the, the diff, the different changes now, in patients, in people's lives because there's a lot of ladies and partners splitting up in their forties and fifties...And then there's a lot more new partners...Maybe, do they see it that actually they don't need, is it because they don't need sexual protection because they've gone past the menopause? ...I'm beginning to wondering if that is it, is that, if that's the reason why it's changed, because of the dynamics that have changed and people getting older, they're no longer staying to that one partner.'Practice Nurse (HCP5)

'I can just feel it now, I can just, you know, remember it in my mind, it's just like putting something

really dry, oh, up something that's all [laughs] sunk in, and it just doesn't work, you just can't do it.'

Non-attender (LS16)

'It wouldn't surprise me if, if a lot of the over fifties don't attend because they're not having regular sex, and therefore they perceive that it would be difficult, or sex is difficult.' GP (HCP14)

I get uncomfortable because my body, my hip locks on me... Well usually you have to lie on the bed don't you and hunch your legs right up and open? I can't expand my legs...they pulled me right down to the edge, had like one of the nurses there and I had to put my feet on her as far up and I mean it, it was painful.' Attender (LS21)

'The laying down, that's not the problem. It, it's the actual physicalness of putting your ankles together. And, and, and opening, opening your knees. It's your joints.' Non-attender (LS15)
EXAMPLES OF SUMMARY STATEMENTS: KEY BARRIERS

TDF DOMAINS

My risk of getting cervical Knowledge cancer is low.

I don't know why I still need a screening test.
Doctors and nurses

think no-one has

a sex life

after sixty.
Role/Identity speculum is painful because everything feels too dry.

I can't get in the right position for the test any more, because it causes physical discomfort.
Beliefs about capabilities 
'When you get to a certain age - age is a factor, illness is a factor - but age is a factor that you become more, more of a sponge to what's going on in the world, and there's not much you can do about dying or preventing your own death, so it becomes less important.' Nonattender with multiple sclerosis (LS4)

"I got to fifty, I went and had my mammogram and they found a lump, so I had to, so it just put me off going to having anything done, I just don't want to know, if I've got anything wrong I don't want to know.'

Non-attender (LS23)

'I don't think you can do anything. I think if you've got something, you get it.'Attender (LS3)

When I became ill, to be honest that was the furthest thing from my mind... it's still too much, it would be

too much for me stresswise to cope with if. If I came and had a smear and got a negative, erm, feedback.'

Non-attender with arthritis and circulatory problems (LS15)

II had gone when I started with the problems after my menopause, to see a lady doctor at the surgery, and to be honest I felt, I felt that she thought I was just being, not stupid, but it wasn't important the fact that I had no sexual intercourse or anything like that and the marriage was breaking down. And she, "Oh, if that's all that's bothering you!", sort of thing. And she was an older lady doctor... I just felt after she'd said that, God I shouldn't be troubling the doctors with things like this.' Non-attender (LS5)

'I think it's quite bad really...it's sixty five then you're kind of cut off... not everyone's sort of past their sell by date and finished with are they really?'Attender (LS21)

'If I speak to women who have menopausal problems or pain with sex, which often you see people, and anyone who's menopausal to be honest, l, if, if they're coming to talk to me about the menopause, I will raise that and say actually use the oestrogen cream and lots of moisturiser. That's what we should be telling everybody... we should be encouraging any women, over fifty to, to treat that as essential part of their healthy life.' GP (HCP14)

I'd have to have a reminder that, you know, you haven't been for this examination for a while... I've just put it to one side and forgotten I've got it... I tend to, I don't mean

conveniently forget because I don't, I just forget, you know... months later I'm going through the bottom of my bag [of admin papers] and thinking - ooh, what's this?'Attender (LS8)

'They've put it in their pile of letters and the day's gone on and they've forgotten or they've rung up and they couldn't get through to the GP surgery and it, it gets forgotten. And then something happens and nobody follows it up and that does happen in, in some practices. And if that happens it can go on and on for years. And it's, and it's modern, busy life, it's understandable.'Practice Nurse (HCP17)

'Time fades, doesn't it really? And I think... if they were to come back after five years when they should have come back, whatever it were that triggered it in the first place is soon forgotten, unless there's some other trigger factor that happens in the meantime.'Practice Nurse (HCP21)
EXAMPLES OF

SUMMARY

STATEMENTS:

KEY BARRIERS
I have too many other health issues - if the test picked up abnormalities, I wouldn't want to go through treatment anyway.

There's nothing I can do to stop myself getting cervical cancer.

If something is wrong, l'd rather not know, I wouldn't cope.
Beliefs about consequences

TDF DOMAINS

I've had problems with dryness since hitting the menopause, but my GP told me these things aren't worth addressing at my age.

I put screening invite letters in my 'to-do' pile and they just get forgotten.
Motivation and goals
Memory,

attention and decision processes 
EXAMPLES OF

SUMMARY

STATEMENTS:

KEY BARRIERS

'We a good rapport with each other... when she actually said "Oh, have you had your smear test letter?" I said "yeah", she said "Well let's book you in". I'd gone for erm a blood pressure test...So each time I got one, I said "Oh I've got my letter" when I'd go for a blood pressure test, she'd book me in rather than me waiting for the receptionist to buff you off and everything else that they do.'Attender (LS13)

From the start [laughs] it just seems...little sort of avenues off. Never mind getting the appointment, never mind actually on the bed and doing what you need to do... The stress I think of having to check in at reception - no-one's there, then she's logging in, I'm thinking "For goodness' sake, woman!"...And then, to top it all, [laughs] I know it's a Well Woman Clinic, and she goes, "Oh, it's important to be, erm, mentally alert!" - "Yeah, I do work in a [customer service] environment, I'm mentally alert, yeah"...I feel oh, just keep, I feel it drags me down. I know I shouldn't say but I feel the whole procedure of reception, seeing different people, different nurses.'Non-attender (LS25)

'Well I suppose if you've got a twenty minute appointment, somebody's not turned up, yeah, you could ring them. But then equally then that can make people feel really bad if they've forgotten. [laughs] And we're not out, I'm not out as a blame culture.'Practice nurse (HCP20)

'Big red letters: "No smear! No smear! No smear! Offer smear! Offer smear!" No one ever discussed why I wasn't going to have it with me. I thought, I'm not bringing it up. [laughs] I don't bloody want it in the first place but, yeah. It was never discussed. Never discussed.' Non-attender (LS2)

'No-one's ever asked me at the surgery where I was before about why I didn't want to do anything or - not that I resent anything - but why, well basically any options... they just took it as mainstream, yeah, you're going to come for a smear.' Non-attender (LS25)

'Ask the question. So remind them first of all that they need it, and then ask them the 'Why' [they don't attend] in a way... and be prepared to do something about it.' GP (HCP1)

'They can treat it...they can take it away by scraping or, you know, whatever, so that that really is my knowledge of it...so yeah, daughters...they're more aware of things like that... When you're growing up in the seventies, you weren't taught anything like that so it's up to you to go out there and find out...but again not always, erm, people there to talk to is there? ...So but yeah, daughters, that's why I know a little bit more about it... because they both had abnormal cells as well.'Attender (LS18)

'Occasionally you will get a couple that are kind of over their fifties. More often than not...their daughters have pushed them into it, because the daughters are kind of coming up to that age for it and they've been for theirs, and if they know their mum's out of date... I have had a couple saying, "Oh my daughter came for hers last week and told me I had to book in for it".'Practice Nurse (HCP19)

'One of my friends...she didn't go for a smear test for years...she'd had letter after letter, and then she said

"I am absolutely terrified", and I said, "Well I'll come with you" and we was in the, in the hospital waiting and she put her coat on and started walking. "Where you going?" She said "I can't stay". I said "Yes you can, you can, it's your body and you need to know that you're clear, do you want to end up bad with cancer or, or something and end up dying with it?" And she went "No". And I said "Well, that's your answer". She was fine, and she still goes now. Attender (LS21)
Communication with my GP practice is important, and it's not always easy.

No-one at my GP surgery ever has ever bothered to ask me why I don't go for screening.

My daughter persuaded me to go for screening.

Friends my own age persuaded me to go for screening/l persuaded a friend to go.
Environmental context and resources
DOMAINS 


\section{EXAMPLES OF DATA}

EXAMPLES OF

SUMMARY

STATEMENTS:

KEY BARRIERS

I've had smears from doctors who treat you like a slab of meat...that turns you off a little bit.'

Attender (LS20)

'It can be a very intense sort of space... women just wanna get it over with...it's a space that can be

quite emotionally charged...it's so emotional, this smear test, and I think that's got to be tackled.'

Non-attender (LS2)

If felt as if she was ramming something into me and it was just extremely, you know, personal and uncomfortable. And I I felt afterwards I'm not going to her again.' Nonattender (LS1)

'The first horrid one I had...she had her back to me for a while, she'd left the thing [speculum] in...I said, "I'm shaking, I can't stop my legs shaking, it hurts like mad!"...it was as if she didn't hear me and she's carrying on, and to me it was like some torture chamber or other.'Non-attender (LS16)

'Ladies of a certain age might think to themselves it was an abusive experience, so therefore that could be a reason why some women are reluctant to go these days...I was terrified. I didn't like my GP, he was - won't mention any names for confidentiality purposes - but erm, don't want to put this in too strong a terms but he made me very uncomfortable.'Attender (LS17)
Whenever l've

had intimate examinations in the past, l've felt uncomfortable/ severely distressed.

I find the screening procedure intimidating and/or impersonal.

Screening reminds me of past traumatic experiences.
TDF DOMAINS

Emotion

\section{LS: Lay Stakeholder; 2. HCP: Health Care Practitioner.}

Stage 2 - Categorisation of barriers and facilitators into theoretical domains: For this project we chose to use the consensus matrix proposed by Michie et a ${ }^{[50]}$ for its clarity and utility. This provided a clear protocol for linking TDF domains with behavioural change techniques. This work has been developed further by Michie et al ${ }^{[52]}$ and Carey et al ${ }^{[53]}$, and intervention developers can now take advantage of an online Theory \& Techniques Too ${ }^{[54]}$. Summary statements representing barriers and facilitators were categorised under the following constructs from the TDF: knowledge, skills, role and identity, beliefs about capabilities, beliefs about consequences, motivation and goals, memory/attention/decision processes, environmental context and resources, social influences, emotions and action planning. Matching data with domains was a subjective process involving discussion and negotiation among the team until consensus was reached.

Stage 3: Stakeholder focus groups: The focus group sessions were audio recorded and transcribed with participants' consent.

Service-user focus group: In focus group 1, patient stakeholders were introduced to the concept of identifying the target behaviour (cervical screening attendance in women over fifty). The research team presented barriers and facilitators data and explained the process of linking these with the domains of the TDF. Behavioural change techniques for addressing the key identified TDF domains were then introduced by the team's behaviour change specialist (JD) (see Table 2). Photographs from popular advertising focusing on lifestyle and health were used to assist an explanation of the principles of behaviour change, and to provoke thought about the focus of an intervention (for example, images of people over fifty engaging in 'healthy' activities, and of interactions between health care professionals and patients). Stakeholders were encouraged to discuss their ideas for intervention content based on the relationship between the target demographic to which they belonged (women over fifty) and the qualitative data statements. Potential modes of delivery were brainstormed with APEASE criteria in mind: affordability, practicability, effectiveness, acceptability, safety and equity ${ }^{[55]}$. 
Table 2

Developing the content of the patient intervention using theoretical constructs from Michie et a[50]. Behavioural change technique
associated with key TDF domains

Persuasive communication

Information regarding

behaviour/outcome

\section{Application of theory to intervention content}

Warm and empathetic tone.

Question and answer format, correcting myths and misunderstandings about screening/its outcomes:

- distinguish myths from facts;

- address age-related questions about the screening process.

Stress management

Illustrate importance of rapport with practitioner/sensitivity of practitioner to experiences of women over fifty.

Modelling/demonstration of behaviour by others

Use social influences meaningful to women over fifty/role modelling of discussing and attending screening by people they can relate to.

Social processes of encouragement, pressure, support

\section{Practitioner stakeholder focus groups}

In focus groups 2 and 3 , the same barriers and facilitators of attendance were presented in categories, shaped by the service-user focus group discussion of practitioner challenges ('patient' barriers, practice barriers, and facilitators of good practice). Stakeholders were asked to identify key challenges in the practice of cervical screening with women over fifty in relation to the barriers to attendance, and to match facilitators to the challenges in a way that characterised 'good practice', evidencing sensitivity to agerelated issues connected with cervical screening. Key elements of these discussions are summarised in Table 3. 
Table 3

Examples of barriers and facilitators from the data which fed in to good practice recommendations.

\begin{tabular}{|c|c|c|}
\hline \multicolumn{2}{|c|}{ Barriers informing outcome } & \multirow{2}{*}{$\begin{array}{l}\text { Outcome } \\
\text { GOOD PRACTICE: KEY CHALLENGES }\end{array}$} \\
\hline $\begin{array}{l}\text { PATIENT } \\
\text { BARRIERS }\end{array}$ & PRACTITIONER BARRIERS & \\
\hline $\begin{array}{l}\text { Examples from } \\
\text { data: } \\
\text { - Non-attenders' } \\
\text { perception of } \\
\text { poor/impersonal } \\
\text { communication } \\
\text { from practitioners. } \\
\text { - Attender and non- } \\
\text { attender } \\
\text { experiences of } \\
\text { problems } \\
\text { discussing sex and } \\
\text { relationship } \\
\text { changes } \\
\text { associated with } \\
\text { aging } \\
\text { with practitioners. } \\
\text { - Experiences of } \\
\text { screening tests } \\
\text { from previous } \\
\text { decades becoming } \\
\text { a 'guiding light' } \\
\text { (non-attender } \\
\text { interviewee) } \\
\text { for decisions about } \\
\text { attendance in the } \\
\text { present. } \\
\text { - Lack of } \\
\text { practitioner } \\
\text { sensitivity to pain } \\
\text { and discomfort } \\
\text { caused by vaginal } \\
\text { dryness. } \\
\text { - Difficulties } \\
\text { keeping } \\
\text { appointments } \\
\text { which } \\
\text { have to be booked } \\
\text { far } \\
\text { in advance. } \\
\text { ation }\end{array}$ & $\begin{array}{l}\text { Examples from data: } \\
\text { - Lack of networking between practice } \\
\text { nurses who carry out cervical } \\
\text { screening. } \\
\text { - Difficulties in making older women } \\
\text { comfortable when they have } \\
\text { menopausal or mobility issues; lack } \\
\text { of continuity with patients in } \\
\text { addressing difficulties. } \\
\text { - Difficulties with } \\
\text { equipment (table height not } \\
\text { adjustable, lighting inadequate, etc). } \\
\text { - Diversity and strength of } \\
\text { expectations among older patients - } \\
\text { may need pragmatic or 'businesslike' } \\
\text { (attender interviewee) approach, or } \\
\text { empathetic and understanding } \\
\text { approach, dependent on screening } \\
\text { history. }\end{array}$ & $\begin{array}{l}\text { 1. How to identify and communicate with non-attenders. } \\
\text { e.g. Draw on person-centred communication procedures (non- } \\
\text { judgemental language/open approach); facilitate networking } \\
\text { between practice nurses around non-attendance. } \\
\text { 2. How to make appointment protocols flexible in a way which } \\
\text { encourages attendance among older women (advice which can } \\
\text { be customised by each GP practice dependent upon capacity). } \\
\text { e.g. Offering a pre-screening appointment to discuss issues; } \\
\text { matching patient with appropriate nurse based on key issues. } \\
\text { 3. How to develop rapport with older women attending for } \\
\text { screening. } \\
\text { e.g. Examples of 'history-taking'techniques - how to talk to } \\
\text { older women about sexual or relationship difficulties connected } \\
\text { with screening avoidance; recognising importance of previous } \\
\text { screening experiences; asking women what they know about } \\
\text { their anatomy (i.e. previous experiences of gynae exams } \\
\text { evidencing difficult positioning of cervix). } \\
\text { 4. How to tailor the screening process to older women's needs. } \\
\text { e.g. Provide instructions for addressing gynaecological issues } \\
\text { such as menopausal dryness, mobility issues/problems } \\
\text { associated with chronic illnesses. Instructions about positioning } \\
\text { women in different ways for the procedure, and use of } \\
\text { speculums/lubrication. }\end{array}$ \\
\hline
\end{tabular}

Transcripts of the focus groups were summarised to guide the written intervention content, which was structured to fit the mode of delivery recommended by stakeholders. The translation of qualitative data into intervention content is described in detail below.

\section{Results}

The majority of the barrier/facilitator data clustered beneath three TDF concepts: beliefs about consequences, social influences and emotion, and smaller clusters of data corresponded with beliefs about capabilities and deficits in knowledge. Examples of data mapped on to the domains are given in Table 3. The mapping framework from Appendix B of Michie et al ${ }^{[50]}$ was used to match the three most prevalent TDF concepts with appropriate behaviour change techniques: persuasive communication and the provision of information regarding behaviour/outcome to address beliefs about consequences, stress management to address difficult emotions, and role modelling and encouragement to harness social influences (see Table 2). 


\section{Service-user stakeholder group}

Stakeholders were introduced to behaviour change techniques related to the processes described above, and how these might be harnessed in the development of intervention content (Table 2). The target behaviour was attendance for cervical screening.

Development of intervention content: There was a strong consensus that the provision of information for women over fifty should focus on questions about screening protocols or uncertainties about continuing screening, and that as 'patients', women do not always know how screening might change with age, or what questions they can legitimately ask:

...if you were going to do, for example a leaflet, sorry, I'm sort of thinking outside the box really... about practitioners or the nurses with the speech bubble, you could sort of do a patient asking 'Does it hurt?'... 'Will I bleed?' ... if they can open up the leaflet, that won't be on the front page obviously but that'd be inside so you might reassure people... I didn't know that there was even a brush that went in me... I didn't even know that, I just thought it was like a little ramrod went in you really, I didn't, [laughs] I don't even know. Stakeholder 1, FG1

Stakeholders stated that the questions included needed to be uniquely pertinent to the experience of aging and menopause. On reconsidering suggested modes of delivery after this discussion, a printed leaflet asking and answering age-related questions about screening was suggested as the most practical way of addressing these concerns, with content guided by experiences of intimate examinations and misunderstandings about screening among women over fifty drawn from the barriers and facilitators data.

In considering how the visual elements of how the question-and-answer section would work, stakeholders emphasised that rapport between women and screening practitioners was central among the facilitator statements. Among the visual material provided to provoke discussion, stakeholders chose a photograph of a nurse and patient to represent the importance of personal communication and the building of rapport: 'there's like some sort of relationship, their heads are right close together' (Stakeholder 2). The consensus was reached that questions and answers could be presented as a conversation between a practice nurse and a 'patient', and that this should be introduced by a service-user story created from the interview data in which a woman over fifty is described talking with friends about cervical screening, to role model attendance behaviour. See Figure 2 for the service-user story and examples of question-and-answer text.

Stakeholders perceived stress management as part of the practitioner's role, citing barriers to attendance which described difficulties in communication with service providers, and emphasised the need for confidence and reassurance: 'I don't do doctors any more, just forget it, you know, it causes aggravation...I'll just stay at home, I'll just Google, it'll be fine!'(Stakeholder 1). Discussion of strategies for stress management led to the identification of the target behaviour for a practitioner intervention: the demonstration of increased sensitivity to age-related issues during the screening process (which included appointment making and pre-screening conversations as well as the test itself), as a way of managing the stress that can be experienced by women over fifty in relation to cervical screening.

Mode of delivery: Service-user stakeholders considered the range of contexts in which information about cervical screening in women over fifty could be effectively disseminated. Ideas included printed messages on supermarket till receipts, leaflets, open days at doctor's surgeries, and the use of role models via media campaigns. Focusing on the APEASE criteria ${ }^{[55]}$, in particular on practicability, it was felt that women's need for privacy could be reflected in a concertina-style leaflet, folded up to hide the content, to fit inside a purse or pocket. Distribution was to occur via primary care or via suitable community venues.

\section{Practitioner stakeholder groups}

In preparation for the practitioner focus groups, barrier statements were categorised under Challenges to attendance and divided into the subcategories 'Patient' barriers and Practice barriers. To guide the discussions, data statements were summarised into four key challenges related to reducing the stress that can be associated with cervical screening for women over fifty (see Table 3): two challenges emerged at the organisational level ( 1 and 2 ) and two at the individual practitioner level ( 3 and 4$)$. Facilitator statements offered examples of potential good practice in each area.

Development of intervention content: The four challenges were discussed in relation to the local demographic contexts of individual GP practices, and developed in more detail to inform the intervention content. Appropriate communication (challenge 1) was linked by practitioners with proactive contact with non-attenders, introducing cervical screening opportunistically during other health

Page $12 / 23$ 
consultations, and allowing responsibility for the decision to rest with the patient. Flexibility (challenge 2) included allowing for prescreening appointments to explore difficulties, and maintaining individual nurse-patient relationships across multiple screening appointments where possible. The development of rapport (challenge 3) was connected with taking time to explore women's past experiences:

That, that is the key and the crux to being able to get a successful smear and for that lady to come back and have that confidence in you, is, is the history taking, I think that's the most important thing. (Stakeholder 1, FG3, Practice Nurse)

It's listening to your lady, ask, actually ask them why, why haven't they come? What's the problem? What can we do to help? It's just listening and getting a rapport. (Stakeholder $3, \mathrm{FG} 3, \mathrm{GP}$ )

Suggestions for tailoring the screening process to women over fifty (challenge 4) included increasing practitioners' knowledge of alternative positioning to accommodate mobility issues, and offering preparative appointments prior to screening to allow the prescription of oestrogen cream to resolve dryness or medication to counteract anxiety, if appropriate.

Mode of delivery: An initial proposal of a laminated A4 sheet detailing the good practice points was rejected by practitioners as unsustainable as it was likely to be overlooked or become lost. Training for cervical screening was seen as onerous by both practitioner groups, and they requested an intervention that was focused and short. The consensus was that the best form of delivery would be a short audio-visual that could be watched on a mobile phone in work breaks, or on a tablet or computer that could also be embedded in the current mandatory on-line training course for cervical screening practitioners in the UK and rewarded by credit contributing to continued professional development (CPD).

\section{Production Of The Interventions}

\section{Service-user intervention}

Content development: The leaflet content comprised of a series of 'patient' questions and practitioner answers based on issues arising from the interview data to address the challenges in cervical screening for women over fifty, and to overcome myths and misunderstandings about the screening process in evidence among the target population. Figure 2 shows examples of questions developed during the patient stakeholder focus group. Answers to the questions were drawn from facilitator data and examples of good practice discussed in practitioner focus groups.

Mode of delivery: A $300 \mathrm{~mm} \times 235 \mathrm{~mm}$ leaflet was produced, targeted at women over fifty. The leaflet folded up into a credit card size between two card covers $(84 \times 54 \mathrm{~mm})$.

\section{Practitioner intervention}

Content development: An 11-minute audio script was developed by AB in consultation with the research team. Table 4 illustrates key issues arising in the focus group discussions that were included in the script. Based on discussions in the stakeholder focus groups, a decision was made to focus the animation around a conversation between two female friends over fifty (one a screening attender, the other a non-attender), using quotations from the interview data to construct a dialogue which systematically illustrated barriers to and facilitators of attendance. The storyline moved through the women's lifecourse, from their twenties to their sixties, to mirror the 'history-taking' described by Stakeholder 1 in FG3, above. The narrative explored the experiences and challenges specific to cervical screening and the facilitators of good practice, as discussed in FG2 and FG3. A women's health expert known nationally to practice nurses and GPs in the UK narrated an introduction to the conversation, and drew out key points for a call to action at the end of the animation. (See Additional File 1: Animation Script). 
Table 4

How key issues from stakeholder focus groups converted into action points in the animation script.

\begin{tabular}{|c|c|}
\hline $\begin{array}{l}\text { GOOD } \\
\text { PRACTICE } \\
\text { POINTS }\end{array}$ & $\begin{array}{l}\text { AREAS OF FOCUS } \\
\text { GROUP DISCUSSION }\end{array}$ \\
\hline $\begin{array}{l}\text { 1.Identify and } \\
\text { communicate } \\
\text { with non- } \\
\text { attenders } \\
\text { who are over } \\
\text { fifty. }\end{array}$ & $\begin{array}{l}\text { - Link cervical screening } \\
\text { with chronic illness } \\
\text { reviews, carer reviews, } \\
\text { etc. } \\
\text { - Ring non-attenders } \\
\text { directly about screening: } \\
\text { listen, inform, explain. } \\
\text { - Have regular practice } \\
\text { meetings raising } \\
\text { patients' individual } \\
\text { issues. } \\
\text { - Raise awareness, } \\
\text { address myths and } \\
\text { misunderstandings. }\end{array}$ \\
\hline $\begin{array}{l}\text { 2.Make } \\
\text { appointments } \\
\text { flexible in a } \\
\text { way which } \\
\text { encourages } \\
\text { attendance in } \\
\text { older women }\end{array}$ & $\begin{array}{l}\text { - Offer repeat } \\
\text { appointments over time } \\
\text { rather than one-off } \\
\text { appointment. } \\
\text { - Offer extended hours } \\
\text { (dependent on } \\
\text { capacity). } \\
\text { - Offer screening } \\
\text { opportunistically. } \\
\text { - Network with other } \\
\text { screen-takers in your GP } \\
\text { practice. } \\
\text { - Allow your patients to } \\
\text { choose their screening } \\
\text { practitioner. }\end{array}$ \\
\hline $\begin{array}{l}\text { 3.Develop } \\
\text { rapport with } \\
\text { older women } \\
\text { attending } \\
\text { for screening. }\end{array}$ & $\begin{array}{l}\text { - Inform patients about } \\
\text { how screening } \\
\text { procedures have } \\
\text { changed. } \\
\text { - Proactively ask women } \\
\text { why they do not attend. } \\
\text { - Talk through the } \\
\text { procedure, inform } \\
\text { women in personal } \\
\text { manner. } \\
\text { - Encourage } \\
\text { collaboration between } \\
\text { older and younger } \\
\text { practice nurses to talk } \\
\text { through age-related } \\
\text { issues. } \\
\text { - GPs to be made aware } \\
\text { of reasons for } \\
\text { appointments in } \\
\text { advance. }\end{array}$ \\
\hline
\end{tabular}

FOCUS OF ANIMATION SCRIPT

Introduction: Professional expert on women's health (General Practice) describes why and how the intervention has been put together.

Central section: A conversation between two women over fifty, voiced by actors, illustrates the challenges that cervical screening practitioners may face with this cohort. The dialogue follows a timeline of screening-related experiences from women's twenties into their sixties, through the decades. Phrases drawn from the qualitative interview data are woven into the dialogue to illustrate the barriers and facilitators of attendance. The narrative explores:

- misunderstandings surrounding the screening test;

- different attitudes towards risk;

- how experiences of intimate examinations in previous decades can affect attitudes towards screening;

- how sex/relationship issues affect attitudes to screening;

- how problems related to menopause and chronic illness can affect practical aspects of the screening test.

Close: The women's health expert summarises the key issues and states a threepoint call to action:

- Prepare: Address physical and psychological issues, build a network of professional support to develop your expertise.

- Listen: Take patient history, build rapport, address psychological and physical challenges.

- Adapt: Where possible and practical, take a flexible approach to appointment booking, and to screening procedures (e.g. positioning). 


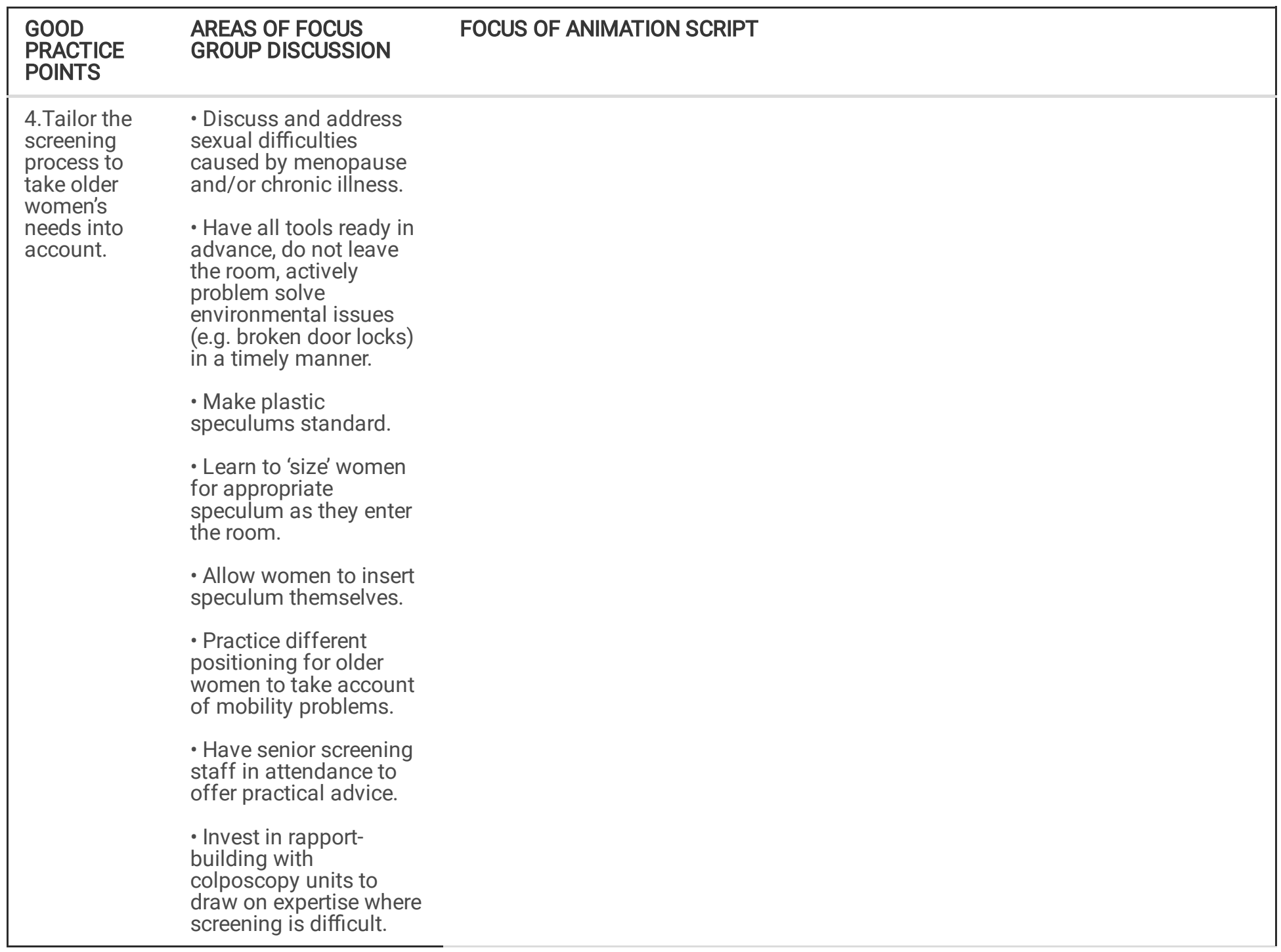

Mode of delivery: An 11-minute educational whiteboard animation for download on a mobile phone and dissemination on remote training platforms.

We are now looking to embed these interventions in the UK primary care setting via general practitioner surgeries and (for the practitioner intervention) online training for GPs and practice nurses as a supplement to training currently in place for cervical screening.

\section{Discussion}

There is evidence that the use of behavioural change theory can increase the success of interventions ${ }^{[56,57]}$. This approach has been used to develop a limited number of cancer screening programmes to increase the chances that knowledge will translate into action $^{[3]}$. Our intention in using a theoretical approach was to explore the determinants that mediate between thinking about attending for cervical screening beyond the age of fifty, and acting on those thoughts. These determinants are shaped by a lack of attention to the psychological and physical changes women experience as they age in generic screening protocols in the UK. This discussion will explore the potential benefits and drawbacks of using a theoretical framework to translate qualitative data into intervention content, and the role of stakeholder engagement in this process.

Recoding of qualitative interviews about patient and practitioner screening experiences allowed the research team to explore barriers and facilitators of engagement based on patient and practitioner priorities. The primary coding framework from the original qualitative study provided a guide to categories of data most likely to contain barrier and facilitator statements. Themes describing emotional difficulties, misunderstandings about cervical cancer and practitioner challenges yielded the majority of the barrier 
statements, and themes exploring women's sexual histories and mother/daughter and patient/practitioner relationship building provided the majority of facilitator statements.

In the original qualitative study, participants were not asked to interpret their experience through the lens of theoretical domains during the interview. The subject of cervical screening was sensitive for interviewees, and focused on eliciting their experiences of intimate screening, to avoid leading the agenda surrounding attendance. We would argue that structuring interview schedules around the domains of the TDF ${ }^{[58]}$ runs the risk of placing the agenda too firmly with the theoretical framework at the expense of exploring the main characteristics of the experience under question.

For our study, the free coding from the original qualitative study analysis aggregated data on barriers and facilitators as they emerged from stakeholders' descriptions of experience. Given that barrier and facilitator statements are quantified when they are assigned to the TDF, the selection of salient domains to pursue with behaviour change techniques was driven by the elements of screening that interviewees chose to talk about in relation to our research question ('How does aging affect women's experiences of decision-making about attendance for cervical screening?'). This hybrid approach ${ }^{[59]}$, with deductive theoretical coding informed by an initial inductive analysis, allowed the stakeholder perspective to remain central and drive the distribution of barrier and facilitator statements in a way which remained true to participants' experiences.

Matching barrier and facilitator statements to the theoretical domains of the TDF was a subjective process involving collaboration and negotiation between the research team in face-to-face meetings. Where the placement of statements was contested, the team were able to reach agreement over which statements best represented which domains. Intervention development via focus groups allowed the team to present and discuss their decision-making with stakeholders, and provided a tier of 'member checking', with participants able to confirm which aspects of the team's decision-making made sense to them ${ }^{[60,61,62]}$. Member checking as a marker of rigour it is acknowledged to be a better fit for some methodologies than others ${ }^{[63]}$ : for stakeholder involvement in intervention design, it is a process which can structure consultation, and a vital tool for exploring how intervention content and mode of delivery might resonate with its intended audience.

The original study on which this paper is based was conducted in 2016-18. The theoretical principles upon which it was based have developed considerably - not only have citations of the TDF increased exponentially since the framework was first created, but the pace of change and refinement has been fierce, leaving published study methodologies lagging behind theoretical developments ${ }^{[53}$, $55,64,65]$. Further exploration of behavioural constructs have been systematic and methodical, and the protocol for developing intervention content from qualitative data described in this paper is replicable using the more recent Theory and Techniques Tool[54] to map the TDF domains on to behavioural change techniques.

\section{Strengths and limitations of the study}

Recruitment for the original qualitative study lacked diversity in terms of the ethnicity. Study material was distributed to all women on GP lists who were more than one year overdue for cervical screening, but all volunteers were white British. The original study did not record the ethnicity of those who were approached for participation, only of those who volunteered for interview (potential interviewees were recruited by practitioners and their details passed on to the research team, with their permission, to maintain confidentiality). While the practitioner focus groups for intervention development were more ethnically diverse, patient data considering demographic and ethnic diversity, while present, was sparse. This limited the exploration of the intersection between ethnicity and age.

Demographic homogeneity is often encountered in stakeholder consultation with older people ${ }^{[65]}$, and our efforts at inclusivity were inevitably guided by the voluntary response to the interview study. We believe that the methodology of intervention development used in this study was recriprocal and iterative, and would work with other similarly homogenous groups in different contexts. In locations where the community-based participatory approaches described in our introduction are not viable for reasons of time and cost, smaller studies with culturally homogenous groups using behavioural change theory could highlight aspects of commonality and divergence and elucidate aspects of demographic diversity in this cohort of women over fifty.

The key strength of the study was the inclusion of the practitioner perspective; the practitioner/service-user relationship is a crucial aspect of the health service context, and this interrelationship of perspectives was a key focus of the qualitative data, which reflected

Page $16 / 23$ 
the central importance of history-taking, relationship building and rapport necessary for women's comfort with the cervical screening process. The centrality of such relationships is also evident in community-based research - for example, in the engagement of community health navigators to facilitate screening ${ }^{[66]}$. The practitioner focus groups in our study raised cultural issues surrounding the intimacy and potential invasiveness of the cervical screening test, and discussions explored how culturally specific research using similar methodologies might further inform practice in demographically diverse areas.

\section{Conclusion}

Despite the broadening literature describing the use of behavioural theory to develop interventions, there is ongoing debate about the efficacy of this approach ${ }^{[44]}$. In the area of cervical screening, existing interventions to encourage attendance are not easily comparable - reviews evidence a great deal of heterogeneity in study designs and a lack of description of the foundations of intervention content, and often fail to include lessons learned from the successful engagement of stakeholders in community based approaches. We would argue that the use of theory can focus the intervention development process and keep intervention content aligned with the priorities of stakeholders. The Theoretical Domains Framework, in combination with the Theory and Techniques

Tool $^{[54]}$, offers a stepwise, auditable protocol for developing intervention content which is amenable to clear reporting and replication in different local contexts. The detailed reporting of protocols for translating qualitative research into intervention content is imperative to achieving transparency, consistency and quality in the material that we chose to test and evaluate. It will also allow a deeper exploration of how stakeholder perspectives might successfully contextualise interventions for specific local populations.

\section{Declarations}

\section{Ethical approvals and consent to participate}

Approval for the study was given by the UK Health Research Authority (IRAS ID 198284) and East Midlands/Leicester Central Research Ethics Committee (REC reference 16/EM/0200). Interview and focus group participants gave written informed consent for participation and for the publication of data gathered in the course of the study.

\section{Consent for publication}

Not applicable.

\section{Availability of data and materials}

Examples of data generated during this study are available within the article and Additional File 1; the original qualitative dataset on which the study is based, and the whiteboard animation, are available from the corresponding author on reasonable request.

\section{Competing interests}

The authors have no competing interests to declare.

\section{Funding}

This study was funded by Yorkshire Cancer Research (Award reference number H393).

\section{Author's contributions}

$A B$ (HYMS) drafted the manuscript for this paper. UM and JP conceived the study and wrote the proposal. UM was principal investigator and lead for the study; JP advised throughout the project. $A B$ (HYMS), $A B$ (Durham), $C D$ and $H C$ analysed data from the original interview study to create the initial dataset; $A B(H Y M S), H C$ and JD conducted the secondary analysis following $B C T$ principles. $A B$ (HYMS), $H C$ and JD conducted FG1, with JD facilitating the BCT co-design process; $A B$ (HYMS) conducted FG2; $A B$ (HYMS) and HC conducted FG3. LJ and AB (HYMS) produced text for the service-user leaflet; AB (HYMS) produced the script for the animation, commissioned the intervention design and managed intervention production. All authors reviewed and revised the paper for intellectual content and approved the final version.

\section{Acknowledgements}

Page $17 / 23$ 
We would like to thank the research sites and participants who participated in the original qualitative study and took part in the codesign process, and those who gave permission for their images and voices to be used in the interventions, including Dr Anne Connolly for the video narration. We would also like to thank Leo Soph Welton at iamhuman for the design and production of the service-user leaflet, Graham Ogilvie at Ogilvie Design for design and production of the animation.

\section{Authors' information}

1 Hull York Medical School, University of Hull, UK. 2 Warwick Medical School, University of Warwick, UK; 3 Durham University, UK; 4 Nuffield Department of Population Health, University of Oxford, UK.

\section{References}

1. Chrysostomou AC, Stylianou DC, Constantinidou A, Kostrikis LG. Cervical cancer screening programs in Europe: The transition towards HPV vaccination and population-based HPV testing. 2018;10(12):729. doi: 10.3390/v10120729.

2. Camilloni L, Ferroni E, Cendales BJ, et al. Methods to increase participation in organised screening programs: a systematic review. BMC Public Health. 2013;13:464. doi:10.1186/1471-2458-13-464.

3. Jepson R, Clegg A, Forbes C, Lewis R, Sowden A, Kleijnen J. Systematic review of the determinants of screening uptake and interventions for increasing uptake. Health Technology Assessment. 2000;4(14):i-vii. doi:10.3310/hta4140. 1-133.

4. Oscarsson MG, Benzein EG, Wijma BE. Reasons for non-attendance at cervical screening as reported by non-attendees in Sweden. Journal of Psychosomatic Obstetrics Gynecology. 2008;29(1):23-31. doi:10.1080/01674820701504619.

5. Marlow LAV, Chorley AJ, Rockcliffe L, Waller J. Decision-making about cervical screening in a heterogeneous sample of nonparticipants: a qualitative interview study. Psycho Oncology. 2018;27(10):2488-93. doi:10.1002/pon.4857.

6. White GE. Older women's attitudes to cervical screening and cervical cancer: a New Zealand experience. Journal of Advanced Nursing. 1995;21:659-66. doi:10.1046/j.1365-2648.1995.21040659.x.

7. Rosser JI, Njoroge B, Huchko MJ. Changing knowledge, attitudes and behaviours regarding cervical cancer screening: The effects of an educational intervention in rural Kenya. Patient Education Counselling. 2015;98(7):884-9. doi:10.1016/j.pec.2015.03.017.

8. Hope KA, Moss E, Redman CWE, Sherman SM. Psycho-social influences upon older women's decision to attend cervical screening: A review of current evidence. Preventive Medicine. 2017;101:60-6. doi:10.1016/j.ypmed.2017.05.002.

9. Lee HY, Lee MH. Barriers to cervical cancer screening and prevention in young Korean women: implications for intervention development. Journal of Transcultural Nursing. 2017;28(4):353-62. doi:10.1177/1043659616649670.

10. Erwin DD, Johnson VA, Trevino M, Duke K, Feliciano L, Jandorf L. A comparison of African American and Latina social networks as indicators for culturally tailoring a breast and cervical cancer education intervention. Cancer Supplement. 2007;109(2):36877. doi:10.1002/cncr.22356.

11. Chorley AJ, Marlow LAV, Forster AS, Haddrell JB, Waller J. Experiences of cervical screening and barriers to participation in the context of an organised programme: a systematic review and thematic synthesis. Psycho-Oncology. 2017;26:161-72. doi 10.1002/pon.4126.

12. NHS. NHS gives women Human Papillomoavirus (HPV) home testing kits to cut cancer deaths. NHS England. 2021. https://www.england.nhs.uk/2021/02/nhs-gives-women-hpv-home-testing-kits-to-cut-cancer-deaths/.

13. PHE. Cervical screening standards data report: 1 April 2018 to 31 March 2019. Public Health England. 2020. https://assets.publishing.service.gov.uk/government/uploads/ system/uploads/attachment_data/file/856927/Cervical_screening_standards_data_report_2018_to_2019.pdf.

14. HIS. Cervical Screening Standards: March 2019. Healthcare Improvement Scotland. 2019. http://www.healthcareimprovementscotland.org/our_work/standards_and_guidelines/stnds/cervical_screening_standards.aspx.

15. PHW. Cervical Screening Wales: Annual Statistical Report 2018-19. Public Health Wales. 2019. https://phw.nhs.wales/news/cervical-screening-wales-annual-report-2018-19-published/.

16. HSC/PHA. Northern Ireland Cervical Screening Programme FACTSHEET: Coverage for the period ending 31 March 2018. Health and Social Care/Public Health Agency. 2018. 
17. Sabates R, Feinstein L. The role of education in the uptake of preventative health care: The case of cervical screening in Britain. Social Science Medicine. 2006;62:2998-3010. doi:10.1016/j.socscimed.2005.11.032.

18. Van Til L, MacQuarrie C, Herbert R. Understanding the barriers to cervical cancer screening among older women. Qualitative Health Research. 2003;13(8):1116-31. doi:10.1177/1049732303255975.

19. Waller J, Jackowska M, Marlow L, Wardle J. Exploring age differences in reasons for nonattendance for cervical screening: a qualitative study. British Journal of Gynaecology. 2012;119:26-32. doi:10.1111/j.1471-0528.2011.03030.x.

20. Freeman M, Waller J, Sasieni P, Lin AWW, Marlow LAV. Acceptability of non-speculum clinician sampling for cervical screening in older women: A qualitative study. Journal of Medical Screening. 2018;25(4):205-10. doi:10.1177/0969141318756452.

21. Castanon A, Landy R, Pesola F, Windridge P, Sasieni P. Prediction of cervical cancer incidence in England, UK, up to 2040, under four scenarios: a modelling study. Lancet Public Health. 2018;3:e34-43. doi:10.1016/S2468-2667(17)30222-0.

22. Hiatt RA, Pasick RJ, Stewart S, et al. Cancer screening for underserved women: the breast and cervical cancer intervention study. Cancer Epidemiology Biomarkers Prevention. 2008;17(8):1945-9. doi:10.1158/1055-9965.EPI-08-0172.

23. Tum SJ, Maree JE, Clarke M. Creating awareness and facilitating cervical and breast cancer screening uptake through the use of a Community Health Worker: A pilot intervention study. 2013; European Journal of Cancer Care. 2013;22:107-116. doi: 10.1111/ecc.12005.

24. Luque JS, Tarasenko YN, Reyes-Garcia C, et al. Saluda es Vida: A cervical cancer screening intervention for rural Latina Immigrant Women. Journal of Cancer Education. 2017;32(4):690-9. doi:10.1007/s13187-015-0978-x.

25. Interis EC, Anakwenze CP, Aung M, Jolly P. Increasing cervical cancer awareness and screening in Jamaica: Effectiveness of a theory-based educational intervention. International Journal of Environmental Research Public Health. 2016;13:53-64. doi:10.3390/ijerph13010053.

26. Krok-Schoen JL, Oliveri JM, Young MS, Katz ML, Tatum CM, Paskett ED. Evaluating the stage of change model to a cervical cancer screening intervention among Ohio Appalachian women. Women Health. 2016;56(4):468-86. doi:10.1080/03630242.2015.1101736.

27. Park K, Hong WH, Kye SY, Jung E, Kim M, Park HG. Community-based intervention to promote breast cancer awareness and screening: The Korean experience. BMC Public Health. 2011;11:468. doi:10.1186/1471-2458-11-468.

28. Hancock L, Sanson-Fisher R, Perkins J, Corkrey R, Burton R, Reid S. Effect of a community action intervention on cervical cancer screening rates in rural Australian towns: the CART project. Preventive Medicine. 2001;32(2):109-17. doi:10.1006/pmed.2000.0776.

29. Gotay CC, Banner RO, Matsunaga DS, et al. Impact of a culturally appropriate intervention on breast and cervical screening among native Hawaiian women. Preventative Medicine. 2000;31(5):529-37. doi:10.1006/pmed.2000.0732.

30. Craig P, Dieppe P, Macintyre S, Michie S, Nazareth I, Petticrew M. Developing and evaluating complex interventions: the new Medical Research Council guidance. BMJ. 2008;337:a1655. doi:10.1136/bmj.a1655.

31. National Institute for Health and Care Excellence. Behaviour change: general approaches. Public health guideline [PH6].. 2007. https://www.nice.org.uk/guidance/PH6.

32. National Institute for Health and Care Excellence. Behaviour change: individual approaches. Public health guideline [PH49].. 2014. https://www.nice.org.uk/guidance/PH49.

33. Hoffmann TC, Glasziou PP, Boutron I, et al. Better reporting of interventions: template for intervention description and replication (TIDieR) checklist and guide. BMJ. 2014;348:g1687. doi:10.1136/bmj.g1687.

34. Webb TL, Joseph J, Yardley L, Michie S. Using the internet to promote health behavior change: a systematic review and metaanalysis of the impact of theoretical basis, use of behavior change techniques, and mode of delivery on efficacy. Journal of Medical Internet Research. 2020;12(1):e4. doi:10.2196/jmir.1376.

35. Taylor N, Conner M, Lawton R. The impact of theory on the effectiveness of worksite physical activity interventions: a metaanalysis and meta-regression. Health Psychology Review. 2012;6(1):33-73. doi:10.1080/17437199.2010.533441.

36. Baker R, Camosso-Stefinovic J, Gillies C, et al. Tailored interventions to address identified determinants of practice. Cochrane Database of Systematic Reviews. 2015;(4):CD005470. doi:10.1002/14651858.CD005470.pub3.

37. Sheeran P, Orbell S. Using implementation intentions to increase attendance for cervical cancer screening. Health Psychology. 2000;19(3):283-9. doi:10.1037//0278-6133.19.3.283.

Page 19/23 
38. Fang CY, Ma GX, Handorf EA, et al. Addressing multilevel barriers to cervical cancer screening in Korean American Women: A randomized trial of a community-based intervention. Cancer. 2017;123(6):1018-26. doi:10.1002/cncr.30391.

39. Escriba-Aguir V, Rodriguez-Gomez BS, Ruiz-Perez I. Effectiveness of patient-targeted interventions to promote cancer screening among ethnic minorities: A systematic review. Cancer Epidemiology. 2016;44:22-39. doi.org/10.1016/j.canep.2016.07.009.

40. Agurto I, Arrossi S, White $S$, et al. Involving the community in cervical cancer prevention programs. International journal of Gynecology Obstetrics. 2005;89:38-45. doi:10.1016/j.ijgo.2005.01.015.

41. Garba RM, Gadanya MA. The role of intervention mapping in designing disease prevention interventions: a systematic review of the literature. PLoS ONE. 2017;12(3):e0174438. doi.org/10.1371/journal.pone.0174438.

42. Lee HY, Koopmeiners JS, Rhee TG, Raveis VH, Ahluwalia JS. Mobile phone text messaging intervention for cervical cancer screening: changes in knowledge and behavior pre-post intervention. Journal of Medical Internet Research. 2014;16(8):e196. doi:10.2196/jmir.3576.

43. Michie S, Carey R, Johnston M, et al. From theory-inspired to theory-based interventions: A protocol for developing and testing a methodology for linking behaviour change techniques to theoretical mechanisms of action. Annals of Behavioral Medicine. 2018;52(6):501-12. doi:10.1007/s12160-016-9816-6.

44. Hagger MS, Weed M. DEBATE: Do interventions based on behavioural theory work in the real world? International Journal of Behavioural Nutrition Physical Activity. 2019;16:36. doi.org/10.1186/s12966-019-0795-4.

45. Bussières AE, Patey AM, Francis JJ, Sales AE, Grimshaw JM. Identifying factors likely to influence compliance with diagnostic imaging guideline recommendations for spine disorders among chiropractors in North America: A focus group study using the Theoretical Domains Framework. Implementation Science. 2012;7:82. doi:10.1186/1748-5908-7-82.

46. Phillips CJ, Marshall AP, Chaves NJ, et al. Experiences of using the Theoretical Domains Framework across diverse clinical environments: A qualitative study. Journal of Multidisciplinary Healthcare. 2015;8:139-46. doi 10.2147/JMDH.578458.

47. Horppu R, Martimo KP, MacEachen E, Lallukka T, Viikari-Juntura E. Application of the Theoretical Domains Framework and the Behaviour Change Wheel to understand physicians' behaviors and behavior change in using temporary work modifications for return to work: A qualitative study. J Occup Rehabil. 2018;28:135-46. doi:10.1007/s10926-017-9706-1.

48. [AUTHORS, 2021].

49. Michie S, Johnston M, Abraham C, Lawton R, Parker D, Walker A. Making psychological theory useful for implementing evidence based practice: a consensus approach. BMJ Quality Safety in Health Care. 2005;14(1):26-33. doi:10.1136/qshc.2004.011155.

50. Michie S, Johnston M, Francis J, Eccles M. From theory to intervention: Mapping theoretically derived behavioural determinants to behaviour change techniques. Applied Psychology. 2008;57(4):660-80. doi:10.1111/j.1464-0597.2008.00341.x.

51. Braun V, Clarke V. Using thematic analysis in psychology. Qualitative Research in Psychology. 2006;3(2):77-101. doi:10.1191/1478088706qp063oa.

52. Michie S, Richardson M, Johnston M, et al. The behavior change technique taxonomy ( 1 1) of 93 hierarchically clustered techniques: building an international consensus for the reporting of behavior change interventions. Ann Behav Med. 2013;46(1):81-95. doi:10.1007/s12160-013-9486-6.

53. Carey RN, Connell LE, Johnston M, et al. Behaviour change techniques and their mechanisms of action: A synthesis of links described in published intervention literature. Annals of Behavioral Medicine. 2019;53:693-707. doi:10.1093/abm/kay078.

54. HBCP. Theory and techniques tool. Human Behaviour Change Project, Centre for Behaviour Change, London. 2020. Available via www.humanbehaviourchange.org.

55. Michie, S., Atkins, L., \& West, R. The Behaviour Change Wheel: A Guide to Designing Interventions. 2014. Silverback Publishing, UK.

56. Steinmetz H, Knappstein M, Ajzen I, Schmidt P, Kabst R. How effective are behaviour change interventions based on the Theory of Planned behaviour? A three-level meta-analysis. Zeitschrift für Psychologie. 2016;224(3):216-33. doi:10.1027/2151$2604 / \mathrm{a} 000255$.

57. Knittle K, Nurmi J, Crutzen R, Hankonen N, Beattie M, Dombrowski SU. How can interventions increase motivation for physical activity? A systematic review and meta-analysis. Health Psychology Review. 2018;12(3):211-30.

58. Atkins $L$, Francis JF, Islam R, et al. A guide to using the Theoretical Domains Framework of behaviour change to investigate implementation problems. Implementation Science. 2017;12:77. doi:10.1186/s13012-017-0605-9.

Page 20/23 
59. Fereday J, Muir-Cochrane E. Demonstrating rigour using thematic analysis: A hybrid approach of inductive and deductive coding and theme development. International Journal of Qualitative Methods. 2006;5(1):80-92.

60. Leininger M. (1994). 'Evaluation criteria and critique of qualitative research studies.' In Morse J, editor Critical issues in qualitative research methods. 1994;95-115. Thousand Oaks, CA: Sage.

61. Cutcliffe J, McKenna H. When do we know that we know?: Considering the truth of research findings and the craft of qualitative research. Int J Nurs Stud. 2002;39(6):611-8. doi:10.1016/S0020-7489(01)00063-3.

62. Sandelowski M. Reembodying qualitative enquiry. Qualitative Health Research. 2002;12(1):104-15. doi:10.1177/1049732302012001008.

63. Birt L, Scott S, Cavers D, Campbell C, Walter. Member checking: A tool to enhance trustworthiness or merely a nod to validation? Qualitative Health Research. 2016;26(13):1802-11. doi:10.1177/1049732316654870.

64. Michie S, van Stralen MM, West R. The behaviour change wheel: A new method for characterising and designing behaviour change interventions. Implementation Science. 2011;6:42. doi:10.1186/1748-5908-6-42.

65. [AUTHOR 2] (Review).

66. Ngoc Nguyen TU, Tanjasari SP, Kagawa-Singer M, Tran JH, Foo MA. Community health navigators for breast- and cervicalcancer screening among Cambodian and Laotian women: Intervention strategies and relationship-building processes. Health Promotion Practice. 2008;9(4):356-67. doi:10.1177/1524839906290251.

\section{Figures}


[FIGURE 1] Translating qualitative data into intervention content using the Theoretical Domains Framework and stakeholder co-design: A worked example from a study of cervical screening attendance in older women

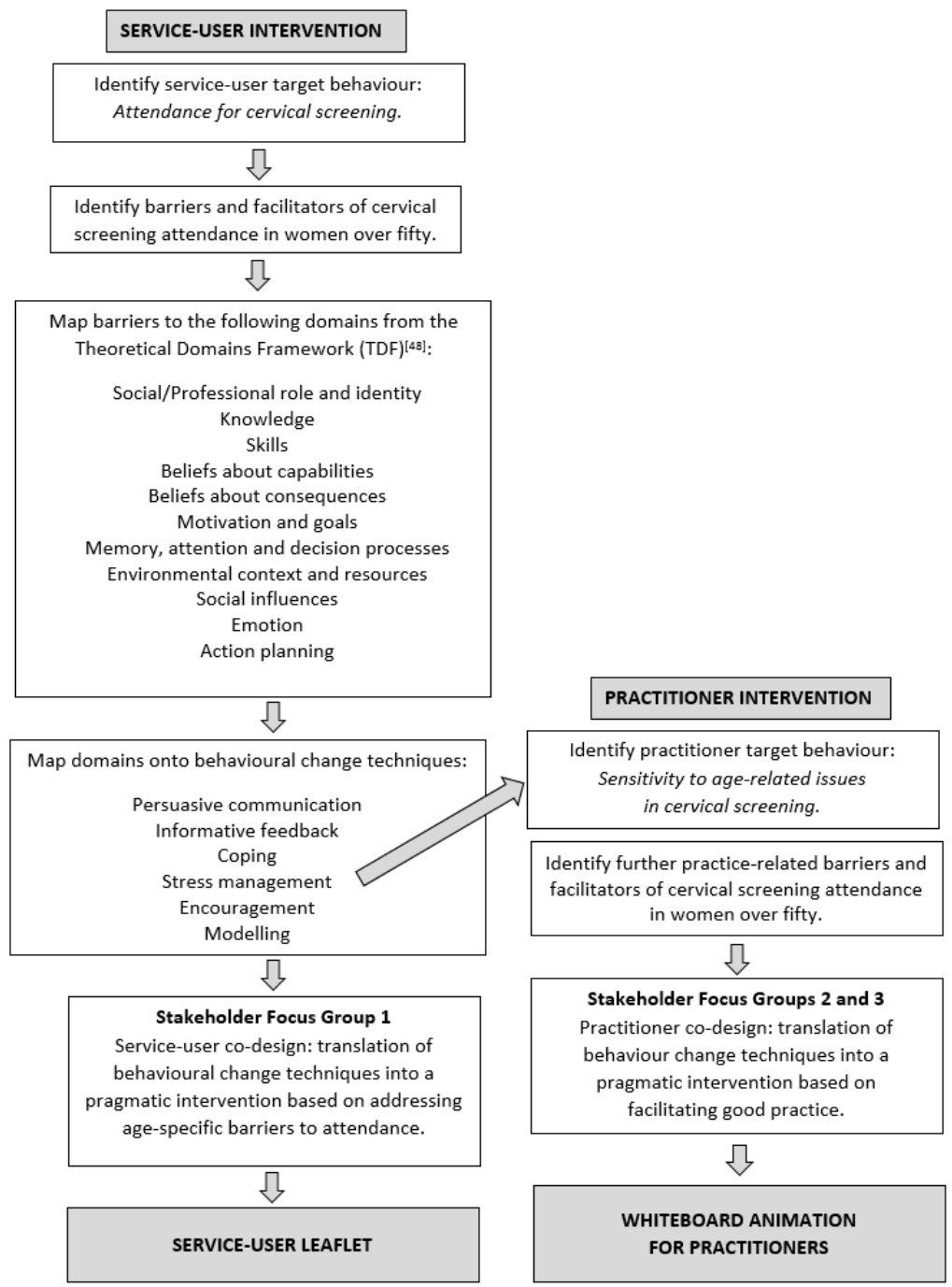

Figure 1

Intervention development flowchart.

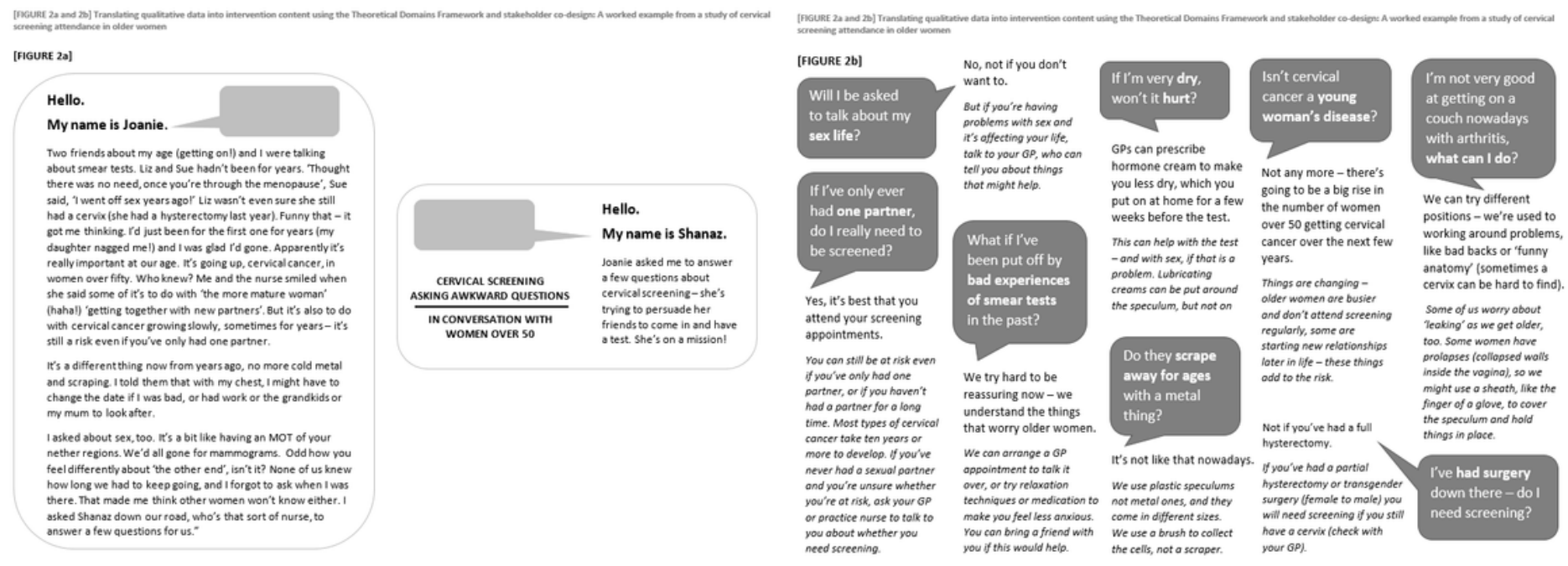


Figure 2

Introducing a screening story and service-user/practice nurse interaction on the service-user leaflet. b Examples of question-andanswer text on the service-user leaflet.

\section{Supplementary Files}

This is a list of supplementary files associated with this preprint. Click to download.

- AdditionalFile1AnimationScript.pdf

- GUIDEDChecklistTranslatingQualitativeData.docx 